\title{
COERÊNCIA: DE LEIBNIZ A HEGEL
}

\author{
Coherence: from Leibniz to Hegel
}

Michele Borges Heldt*

Resumo: : Enquanto Leibniz tenta aproximar sua filosofia aos princípios da matemática, através da formulação de um modelo científico que em última instância reduz tudo o que existe a uma substância única e imutável (mônada), Hegel traz a consciência humana para o primeiro plano, ordenando todos os demais elementos em categorias que se desenvolvem a partir da reflexão. Entretanto, ambas as teorias conservam uma característica em comum: uma certa coerência, uma tendência ao equilíbrio, que para Leibniz faz parte da natureza de cada mônada, ao passo que, para Hegel, a coerência é fundamental e inerente à consciência humana. Eis aqui a ideia central do presente artigo, estudar de que modo essa harmonia se desenvolve em ambas as teorias, analisando suas principais características e seus pontos de divergência e convergência.

Palavras-chave: Substância. Mônada. Consciência. Reflexão. Equilíbrio. Coerência.

\begin{abstract}
While Leibniz attempts to approximate his philosophy to the mathematical principles, by formulation of a scientific model that in the last instance reduces everything that exists a one single and unchanging substance (monade), Hegel brings the consciousness for the foreground and ordering the other elements in categories that are developed from the reflection. However, both theories keeps a characteristic in common: a certain coherence, a tendency to equilibrium, that for Leibniz compose the nature of each monade, while for Hegel, coherence is inherent in human consciousness. Here is the central idea of this article, study how this trend develops in both theories, analyzing its main characteristics and their points of divergence and convergence.
\end{abstract}

Keywords: Substance. Monade. Consciousness. Reflection. Equilibrium. Coherence.

* Doutoranda em Filosofia pela UNISINOS. Bolsista do programa Capes-Prosup. Contato: heldt.michele@ hotmail.com

\begin{tabular}{|c|c|c|c|c|c|}
\hline intuitio & $\begin{array}{c}\text { ISSN } \\
1983-4012 \\
\end{array}$ & Porto Alegre & Vol. $9-\mathrm{N}^{\circ} .1$ & $\begin{array}{l}\text { Julho } \\
2016 \\
\end{array}$ & p.53-67 \\
\hline
\end{tabular}




\section{Introdução}

O objetivo central do presente artigo é fazer um estudo comparativo entre as filosofias de Leibniz e Hegel, buscando, com isso, compreender como o tema da coerência se desenvolve em ambas as teorias, e quais os seus principais pontos de divergência e de convergência sobre o tema.

Leibniz foi pioneiro ao desenvolver uma nova forma de estudo do pensamento humano, vinculando o funcionamento do mesmo às suas pesquisas sobre análise combinatória, uma das áreas da matemática responsável pela análise de combinações possíveis, com base em um conjunto de procedimentos.

A partir da análise combinatória, Leibniz formulou um modelo científico que é o precursor teórico da computação moderna: todo raciocínio, verbalizado ou não, é redutível a uma combinação ordenada de elementos como números, palavras, sons e/ou cores. Essa premissa infere que o pensamento, em sua formulação, necessita de um grau mínimo de coerência ${ }^{1}$, onde alguns elementos básicos se articulam para a formação do raciocínio. Nesse sentido, pode-se dizer que a filosofia de Leibniz antecipou em dois séculos os estudos sobre lógica, metafísica e filosofia da linguagem.

Investigando o funcionamento do pensamento humano sob o ângulo da matemática, e com base na análise de possíveis combinações elementares, Leibniz classificou o agir dos indivíduos dentro da cadeia causal do mundo como "causas eficientes", ao passo que a infinidade de inclinações e disposições passadas e presentes e que conduzem os mesmos a determinadas ações ele chamou de "causas finais".

As causas eficientes referem-se às relações de causa e efeito e aos fatores causais que levam o indivíduo a uma determinada ação, onde a relação entre um evento A (causa) e um segundo evento B (efeito) aponta para uma relação de causalidade em que o segundo evento é uma consequência do primeiro. São relações causais que ocorrem de forma necessária. Já nas causas finais, figuram as ações movidas por alguma razão e/ou motivo oriundo da vontade do indivíduo e não diretamente da necessidade.

Desse modo, o âmbito das causas finais é bem mais amplo, pois se refere a tudo aquilo que pode ser como pode não ser, portanto deve compreender-se a partir do motivo da sua escolha. Onde houver escolha, onde se puder pressupor uma vontade, há sempre, portanto, uma causa final. São relações causais que ocorrem de forma contingente, uma vez que sempre podem ou não ocorrer.

No entanto, seguindo esse raciocínio, conclui-se que qualquer animal pode agir por necessidade e/ou de forma contingente, então Leibniz acrescenta em sua teoria mais um elemento importante que é a reflexão. A capacidade de reflexão é o que diferencia o animal humano dos demais e é essa capacidade

\footnotetext{
${ }^{1}$ Mais do que possuir um significado de nexo e ordem, a etimologia da palavra coerência vem do latim cohaerens, que significa "juntar, unir". Também no presente artigo a palavra coerência assume esses dois sentidos: na filosofia leibniziana, coerência remete à ideia de ordem entre os elementos. Já em Hegel, coerência aproxima-se muito mais de sua etimologia, assumindo o sentido daquilo que é necessário para que haja ligação entre um momento e outro
}

\begin{tabular}{|c|c|c|c|c|c|}
\hline intuitio & $\begin{array}{c}\text { ISSN } \\
1983-4012\end{array}$ & Porto Alegre & Vol.9- $\mathrm{N}^{\mathrm{o}} .1$ & $\begin{array}{l}\text { Julho } \\
2016\end{array}$ & p.53-67 \\
\hline
\end{tabular}


que, quando operada, caracteriza uma ação como livre. Os homens têm a capacidade de pensar a ação e saber por que agem, portanto, a partir da reflexão detém o poder de escolha. Para Leibniz, é a capacidade de reflexão que diferencia os homens das demais criaturas. No entanto, em seu princípio, todas as coisas são constituídas a partir do que ele chamou de "mônadas".

Mônada é um termo oriundo da palavra monas, que em grego significa unidade. Isso porque, segundo Leibniz, a essência ontológica da mônada é sua simplicidade irredutível, pois sua constituição é essencialmente substancial e não material, portanto não pode ser separada em partes. Enquanto unidade, cada mônada preserva a sua independência e as relações entre as mônadas são somente relações aparentes.

As mônadas não são necessariamente diminutas: o ser humano, por exemplo, é constituído por uma mônada, e por mais que interaja com os outros indivíduos e com o mundo, para Leibniz, cada indivíduo é um ser único que carrega consigo diferentes impressões. Eis aqui a principal diferença entre as filosofias de Hegel e de Leibniz: ao passo que, na filosofia hegeliana, tudo somente se dá em relação e a consciência de cada indivíduo depende dessas relações para se desenvolver, em Leibniz cada indivíduo constitui uma mônada, e por mais que esta estabeleça inúmeras relações, o seu modo de entender as informações e experiências provenientes dessas interações é sempre único.

Em Leibniz, mesmo que o processo mental pelo qual a consciência se desenvolve seja semelhante entre os indivíduos, essa semelhança é referente ao processo e não à consciência em si, a qual ele chamou de alma. A alma, para Leibniz, é uma substância simples acompanhada não só de percepção, como também de memória.

(...) segue-se [da noção de substância individual] que toda alma é como um mundo à parte, independente de qualquer outra coisa (...), que [a alma] é não só imortal e, por assim dizer, imperecível, mas que guarda em sua substância restos de tudo o que lhe acontece. ${ }^{2}$

Para Leibniz, a origem de todas as coisas está em uma substância simples e que, portanto, em última instância não pode ser decomposta, onde cada mônada é constituída por uma substância estritamente individual.

Já Hegel, pelo contrário, entende que a consciência, ao se utilizar da linguagem que é formada a partir de conceitos universais, passa a ser também universal porque compartilha desses conceitos com outras consciências. Além disso, Hegel entende que, ao concretizar suas ideias, compartilhando com outros indivíduos o resultado de suas ações, a consciência recai uma vez mais no campo da universalidade.

Em Leibniz, por outro lado, cada consciência é una, construída através da linguagem sim, mas também de impressões e vivências que são únicas, pois mesmo que vários indivíduos passem pela mesma

${ }^{2}$ LEIBNIZ, 1985, p. 27.

\begin{tabular}{|c|c|c|c|c|c|}
\hline intuitio & $\begin{array}{c}\text { ISSN } \\
1983-4012\end{array}$ & Porto Alegre & Vol.9- $\mathrm{N}^{\mathrm{o}} .1$ & $\begin{array}{l}\text { Julho } \\
2016\end{array}$ & p.53-67 \\
\hline
\end{tabular}


experiência, é possível que cada um deles tenha uma percepção diversa sobre ela. Segundo Leibniz, cada indivíduo é um ser único, e mesmo interagindo constantemente com outros indivíduos e produzindo inúmeras coisas através dessa interação, em última instância cada mônada é constituída por uma substância simples, que não pode ser replicada ou composta e que, portanto, é única.

Nesse sentido, cada consciência se apresenta como um mundo à parte, próprio, mas também como unidade primordial que compõe todas as coisas.

(...) que não se divide uma substância em duas, nem de duas se faz uma e que assim o número das substâncias não aumenta nem diminui naturalmente, embora sejam frequentemente transformadas. ${ }^{3}$

Nesse ponto, a filosofia leibniziana segue o caminho oposto à de Hegel, pois Leibniz parte sempre do mais simples para o mais complexo ao entender que a consciência busca sim, no exterior, uma série de informações necessárias para que ela possa conhecer e compor o cenário a sua volta, no entanto, essa consciência em si jamais será um conceito formado a partir da universalidade.

O conceito, em Leibniz, é somente o instrumento que a consciência utiliza para conhecer o mundo, porém a consciência em si é uma substância simples e una que antecede o próprio momento da conceitualização porque, no momento em que ela acata a determinação do conceito, a consciência já deixou de ser ela mesma para entrar no campo das determinidades. No entanto, sua matriz permanece intocável, substância eterna e imperecível.

Sob a ótica da filosofia leibniziana, o próprio devir hegeliano, isto é, o processo mental pelo qual algo vem a ser para a consciência, não seria possível se esta não fosse única, visto que a cada suprassunção, a consciência necessita retornar a si mesma - ou seja, sua substância simples que não contém em si nenhuma diferença e mediação -, para novamente entrar no modo do conceito pelo qual a coisa vem a ser algo para a consciência mesma. Assim sendo, para Leibniz a consciência é uma mônada, isto é, uma substância simples, mas pré-existente, da qual se origina um mundo que, aliás, também será único, pois cada mônada engendrará o seu próprio mundo.

Já sob a perspectiva da dialética hegeliana, a mônada de Leibniz é o equivalente à abstração absoluta. Isso porque, para Hegel, a consciência sem mediação nada mais é do que o puro nada, na medida em que simplesmente não consegue se desenvolver.

Entretanto, essas duas teorias opostas possuem um ponto em comum, qual seja, tanto a alma leibniziana (entendida como singular), como a consciência hegeliana (vista como universal), possuem em si uma certa "tendência ao equilíbrio". Para Leibniz, essa tendência é intrínseca à natureza de toda mônada e faz com que, dentro da cadeia de possibilidades pré-existentes, ela busque efetivar sempre o que há de melhor. Já em Hegel, a tendência ao equilíbrio provém do constante jogo de forças entre o singular e o

\footnotetext{
${ }^{3}$ LEIBNIZ, 1985, p. 27.
}

\begin{tabular}{|c|c|c|c|c|c|}
\hline intuitio & $\begin{array}{c}\text { ISSN } \\
1983-4012\end{array}$ & Porto Alegre & Vol.9- $\mathrm{N}^{\circ} .1$ & $\begin{array}{l}\text { Julho } \\
2016\end{array}$ & p.53-67 \\
\hline
\end{tabular}


universal, imposto pela própria consciência em sua busca por conhecimento. Entrementes, em ambas teorias tal tendência se efetiva por meio da coerência - no sentido de ordem para Leibniz e de relação para Hegel - conforme será tratado nos tópicos a seguir.

1. Equilíbrio em Hegel: a coerência enquanto necessidade absoluta

Na filosofia hegeliana, a tendência ao equilíbrio se desenvolve por meio de momentos dialéticos, onde a insuficiência de um momento leva sempre a um outro. Desde o início de seu desenvolvimento, a consciência busca conhecer a verdade sobre o mundo à sua volta. No entanto, ela não consegue obter esse saber por si mesma, de modo isolado, mas somente em relação. Essa relação se dá através da correspondência entre a coisa e o seu conceito, que é o modo pelo qual a consciência adquire conhecimento.

Para que a consciência conheça o objeto visado, o mesmo deve corresponder ao seu conceito, caso contrário, se esvanece em contradição. Em Hegel, o desenvolvimento da consciência está atrelado à constante busca pela superação da contradição, e isso infere duas coisas: primeiro que, na dialética hegeliana, nada se dá de forma isolada, mas somente em relação. Segundo que, para que essa relação se desenvolva, é necessário que haja alguma correspondência entre os seus elementos

(...) o objeto que a individualidade experimenta como sua essência não tem conteúdo nenhum. É o que se chama necessidade; com efeito, necessidade, destino, etc., são justamente uma coisa que ninguém sabe dizer o que faz, quais suas leis determinadas e seu conteúdo positivo. Porque é o conceito absoluto intuído como ser, a relação simples e vazia, mas irresistível e imperturbável, cuja obra é apenas o nada da singularidade. ${ }^{4}$

Hegel afirma que, o que a individualidade experimenta como sua essência, não tem conteúdo algum porque a essência enquanto reflexão pura, não possui ainda nenhuma mediação, logo, é vazia de conteúdo. A consciência carrega consigo essa necessidade de mediação, e esta, é o seu destino porque ela simplesmente não consegue se desenvolver de forma plena sem esse movimento. É intrínseca à consciência essa necessidade de relação com o ser-outro, o qual representa tudo aquilo que é exterior à consciência mesma.

Esse impulso inerente à consciência, segundo Hegel, é algo que ninguém sabe explicar exatamente de onde vem. No entanto, suas leis regem o próprio ser, na medida em que a existência de algo para a consciência passa primeiro por esse processo de determinação. É o ser no modo do conceito, e sem este, é para Hegel uma relação simples e vazia porque a consciência não consegue conhecer a verdade da

\footnotetext{
${ }^{4}$ HEGEL, 2007, p. 258.
}

\begin{tabular}{|c|c|c|c|c|c|}
\hline intuitio & $\begin{array}{c}\text { ISSN } \\
1983-4012\end{array}$ & Porto Alegre & Vol.9- $\mathrm{N}^{\mathrm{o}} .1$ & $\begin{array}{l}\text { Julho } \\
2016\end{array}$ & p.53-67 \\
\hline
\end{tabular}


coisa em si, mas apenas a conhece por meio de sua determinação. E é somente assim que poderá conhecêla, o que para a filosofia hegeliana não é um problema, mas sim a forma natural da consciência conhecer as coisas à sua volta.

Nessa concepção, o nada da singularidade refere-se justamente à consciência que, sem mediação isto é, sem a imposição da identidade com o ser-outro - permanece em um vazio oriundo da falta de conhecimento visto que, na filosofia hegeliana, o que a consciência não conhece, para ela nada é.

A necessidade é essa conexão firme, porque as coisas conectadas são essencialidades puras, ou abstrações vazias: unidade, diferença e relação são categorias; cada uma delas nada é em si e para si, mas só em relação ao seu contrário; portanto não podem separar-se uma da outra. É através de seu conceito que mutuamente se referem, pois as categorias são os conceitos puros mesmos: essa relação absoluta e esse movimento constituem a necessidade. ${ }^{5}$

Em Hegel, a necessidade é uma conexão firme porque faz parte da natureza da consciência humana essa necessidade que é de relação, onde as coisas isoladas são apenas abstrações vazias, e somente adquirem algum sentido conectadas umas às outras. A formação do próprio pensar depende dessa relação, pois também os pensamentos não se dão de forma isolada, mas é um pensamento que leva a outro de forma instantânea.

Na filosofia hegeliana, o movimento dialético se dá sempre através de momentos, onde a unidade é a consciência em si, a diferença é tudo aquilo que está fora dela mesma, e a relação se dá sempre entre a consciência e sua diferença.

O movimento descrito acima faz parte do primeiro momento da dialética hegeliana, onde as categorias não conseguem separar-se uma da outra porque a consciência necessita dessa mediação para se desenvolver, e esta, é uma relação entre os contrários porque, para a consciência, tudo aquilo que vem de fora simplesmente não faz parte dela mesma.

Ao almejar conhecer a verdade do objeto visado, a consciência busca em sua base referencial informações acerca desse objeto, e estas, nada mais são do que conceitos adquiridos por meio da linguagem, que antes de serem singulares, são universais na medida em que vem do exterior e de um conhecimento previamente desenvolvido, o qual servirá de base para a formação de seu próprio pensar. Essa relação que se dá de forma contínua entre o singular e o universal é a própria necessidade que, para Hegel, é absoluta.

A individualidade somente singular, que só tem, de início, o puro conceito de razão por seu conteúdo, em vez de precipitar-se da teoria morta para a vida, o

${ }^{5}$ HEGEL, 2007, p. 259.

\begin{tabular}{|c|c|c|c|c|c|}
\hline intuitio & $\begin{array}{c}\text { ISSN } \\
1983-4012\end{array}$ & Porto Alegre & Vol.9- $\mathrm{N}^{\circ} .1$ & $\begin{array}{l}\text { Julho } \\
2016\end{array}$ & p.53-67 \\
\hline
\end{tabular}


que fez foi jogar-se na consciência de sua própria carência-de-vida, e só participa de si como necessidade vazia e alheia - como efetividade morta. ${ }^{6}$

Na dialética hegeliana, a necessidade, além de ser uma necessidade de relação, refere-se também à necessidade que a consciência tem de passar por todos os momentos dialéticos para se desenvolver de forma plena, pois no primeiro deles - o movimento entre o ser-aí, o ser-outro e a consciência-de-si - a mesma ainda não consegue reconhecer sua condição essencialmente universal, pois continua impondo a cisão entre o singular e o universal na medida em que, mesmo acatando as determinações do ser-outro, ainda reconhece este como algo que está fora dela mesma, portanto ainda não faz parte de si.

Nesse primeiro momento dialético, o conhecimento é baseado somente no fenômeno, uma vez que a consciência ainda não conseguiu desenvolver qualquer reflexão mais aprofundada. Conhecendo a coisa somente por meio de sua aparência, a consciência continua negando o universal e desejando conhecer a coisa de modo singular. Dessa forma, a mesma recai na necessidade vazia e alheia de um saber que nega o universal, mas que, ao mesmo tempo, não consegue conhecer as coisas a sua volta senão por meio da universalidade, então permanece na representação.

Essa passagem de seu ser vivo para a necessidade sem-vida se lhe manifesta, pois, como uma inversão, que por nada é mediatizada. O mediador deveria ser algo em que os dois lados fossem um (só) - portanto, a consciência que conhecesse um momento no outro: - seu fim e agir no destino, e seu destino no seu fim e agir; sua essência própria nessa necessidade. Porém essa unidade é para essa consciência justamente o prazer mesmo, ou o sentimento singular simples. A passagem do momento desse seu fim ao momento de sua essência verdadeira é para ela um puro salto no oposto, pois esses momentos não estão contidos e ligados no sentimento, mas só no puro $\mathrm{Si}$, que é um universal ou pensar. ${ }^{7}$

Para Hegel, o pensamento está diretamente ligado à lógica e à racionalidade, pois se desenvolve de maneira instantânea através de um movimento de suprassunção ${ }^{8}$ de determinações universais, internalizadas por meio da linguagem e do raciocínio lógico. Assim sendo, de acordo com a concepção hegeliana, o fundamento do pensar não se dá por meio dos sentimentos, mas sim por meio de um processo mental lógico, mas como ele ocorre de forma instantânea para a consciência, não é captada pelo indivíduo, que apenas percebe aflorar os sentimentos que daí decorrem.

\footnotetext{
${ }^{6}$ HEGEL, 2007, p. 259

${ }^{7}$ HEGEL, 2007, p. 259.

8 A suprassunção refere-se à tradução do termo "Aufhebung" que é um dos conceitos mais importantes para o entendimento da dialética hegeliana. Em Hegel, em cada etapa que a consciência avança, os ensinamentos do momento anterior são ultrapassados, mas também de certo modo conservados, na medida em que são analisados de um ponto de vista mais elevado. Isso leva ao desenvolvimento de um saber que não se torna fechado e estático enquanto pretensão de verdade, mas que capta o movimento, o "vir-a-ser" do próprio conhecimento. Esse movimento é o aufhebung, um movimento de suprassunção das determinidades anteriores, mas que, ao mesmo tempo, permanece aberto para novas determinações.
}

\begin{tabular}{|c|c|c|c|c|c|}
\hline intuitio & $\begin{array}{c}\text { ISSN } \\
1983-4012\end{array}$ & Porto Alegre & Vol.9- No.1 & $\begin{array}{c}\text { Julho } \\
2016\end{array}$ & p.53-67 \\
\hline
\end{tabular}


Desse modo, o desejo de conhecer a verdade da coisa em si é percebido de modo simples e singular, mas o movimento que ocorreu antes dele não. Nesse ponto, Hegel faz uma crítica à epistemologia, inferindo que a construção do saber seria facilitada se o sujeito reconhecesse que a sua consciência depende de uma base conceitual que antes de tudo é universal, colocando, desse modo, o universal e o singular do mesmo lado, ao invés de impor uma cisão entre eles. É justamente por conta dessa separação que a passagem do momento em que a consciência deseja conhecer a verdade da coisa em si ao momento do saber efetivo é, para Hegel, um "salto no oposto", porque, ao menos de início, a consciência não consegue admitir que a determinação vinda de fora já faz parte dela mesma. Na dialética hegeliana, esse "voltar a si certa de si mesma" ocorre somente no final da primeira tríade, com o vir-a-ser da consciência-de-si.

A consciência-de-si é alcançada no momento em que a mesma deixa de basear o seu conhecimento apenas no fenômeno oriundo da representação inicial, e passa de fato a refletir acerca dessa representação, reconhecendo-se como razão universal na medida em que também reconhece o objeto visado.

De acordo com a filosofia hegeliana, em decorrência de seu fundamento conceitual, o modo da consciência perceber o mundo é primeiramente universal, mas como a passagem do universal para o singular se dá instantaneamente para a consciência, inicialmente a mesma acredita que o seu pensar é estritamente individual. A consciência somente se tornará consciência-de-si após passar pelos momentos dialéticos necessários para que ela consiga reconhecer que a determinação imposta pelo ser outro equivale ao seu próprio conceito. E, mesmo após tornar-se consciência-de-si, essa articulação dialética continua, e é justamente esse jogo de forças entre o singular e o universal que traz para a consciência o equilíbrio necessário para que ela consiga avançar em conhecimento, por meio da coerência existente entre a coisa e o seu conceito, a própria racionalidade segundo Hegel, que permite à consciência formular e ordenar seus pensamentos.

Já essa coerência vem da necessidade absoluta que, para Hegel, nada mais é do que um movimento natural da consciência em seu processo evolutivo. Isto é, a necessidade (de relação) é a condição absoluta para que as coisas venham a ser algo para a consciência.

2. Equilíbrio em Leibnz: o princípio da harmonia preestabelecida

Conforme já explanado, de acordo com a filosofia de Leibniz, cada indivíduo é formado por uma mônada, cuja constituição principal não é a forma, o corpo, mas sim sua forma substancial, sua alma. Inclusive os fenômenos formados a partir da percepção são, para Leibniz, passíveis de dúvida quanto à sua verdadeira natureza, por isso que, de acordo com a sua teoria, as sensações e percepções oriundas de cada

\begin{tabular}{|c|c|c|c|c|c|}
\hline intuitio & $\begin{array}{c}\text { ISSN } \\
1983-4012\end{array}$ & Porto Alegre & Vol.9- $\mathrm{N}^{\circ} .1$ & $\begin{array}{l}\text { Julho } \\
2016\end{array}$ & p.53-67 \\
\hline
\end{tabular}


mônada não constituem uma substância em si (muito embora possam transformá-la, mas sempre a partir dela mesma), porque dependem diretamente de sua representação.

(...) toda a natureza do corpo não consiste somente na extensão, isto é, na grandeza, figura e movimento, mas que importa necessariamente reconhecer nela algo que tenha relação com as almas e que se designa habitualmente por forma substancial, ainda que não altere em nada os fenômenos (...). Pode até demonstrar-se que a noção da grandeza, da figura e do movimento não é tão distinta como se imagina, e que encerra algo de imaginário e de relativo às nossas percepções, como acontece ainda (embora muito mais) com a cor, o calor, e outras qualidades semelhantes, de que se pode duvidar se se encontram verdadeiramente na natureza das coisas fora de nós. Eis porque estas espécies de qualidades não poderiam constituir nenhuma substância. E se não há outro princípio da identidade nos corpos, à exceção do que acabamos de dizer, nunca um corpo subsistirá mais do que um momento. ${ }^{9}$

Conforme já exposto, Hegel radicalizou essa ideia afirmando que não é possível aos indivíduos conhecerem a verdade da coisa em si, mas somente por meio de seu conceito. Então, quando Leibniz diz na citação acima que "nunca um corpo subsistirá mais do que um momento" refere-se diretamente ao momento que antecede a representação (a certeza sensível de Hegel), onde o indivíduo visa o objeto e busca em sua base conceitual as informações necessárias para conhecê-lo. Mas, ao proceder dessa forma, recorre instantaneamente ao conceito acerca desse objeto, não conseguindo conhecer o que ele é em si. Ora, de fato em Leibniz esse visar não dura mais do que um momento mesmo, porque tudo que daí decorre não passa de representação.

No entanto, Leibniz faz uma clara distinção entre a representação feita por um animal irracional e um ser humano que possui a capacidade de não apenas identificar as coisas, agindo por instinto, mas de aprender e de raciocinar acerca de seus atos. "Contudo, as almas e as formas substanciais dos outros corpos são muito diferentes das almas inteligentes, as únicas que conhecem as suas ações e que não só não perecem naturalmente, mas até guardam sempre o fundamento do conhecimento do que são". (Leibniz, 1985, p. 32).

Mas, contrariamente à filosofia de Hegel, cuja consciência tanto se forma quanto recai sempre na universalidade, para Leibniz uma mônada é sempre una, pois apesar de interagir constantemente com outras mônadas e até mesmo se transformar a partir dessas interações, cada substância engendra o seu próprio mundo com base em suas vivências e percepções.

(...) toda substância é como um mundo inteiro (...) que cada uma exprime à sua maneira, quase como uma mesma cidade é diversamente representada segundo as diferentes posições de quem a vê". (...) uma substância particular nunca atua sobre outra substância particular e nem sequer sofre a sua ação, se se considerar

${ }^{9}$ LEIBNIZ, 295, p. 32.

\begin{tabular}{|c|c|c|c|c|c|}
\hline intuitio & $\begin{array}{c}\text { ISSN } \\
1983-4012\end{array}$ & Porto Alegre & Vol.9- $\mathrm{N}^{\mathrm{o}} .1$ & $\begin{array}{l}\text { Julho } \\
2016\end{array}$ & p.53-67 \\
\hline
\end{tabular}


que o que acontece a cada uma não é senão consequência da sua mera ideia ou noção completa (....). ${ }^{10}$

E Leibniz, assim como Descartes, considerava que a memória e a racionalidade são um presente de Deus aos homens, e que essa capacidade faz com que cada mônada exprima na realidade suas próprias percepções, formadas tanto a partir de experiências passadas como futuras, uma vez que a natureza de cada mônada carregaria consigo a contingência de tudo aquilo que pode vir a lhe ocorrer, encerrando em sua própria natureza inúmeras possibilidades (possíveis de efetivação). "Pode mesmo dizer-se que toda a substância traz de algum modo a marca da sabedoria infinita e da onipotência de Deus, e a imita tanto quanto é capaz. Pois exprime, ainda que confusamente, tudo o que acontece no universo, passado, presente ou futuro, o que tem alguma semelhança com uma percepção ou conhecimento infinito. (Leibniz, 1985, p. 28).

\begin{abstract}
Dissemos que a noção de uma substância individual encerra, de uma vez por todas, tudo o que sempre lhe pode acontecer e que, ao considerar esta noção, se pode ver aí tudo o que dela verdadeiramente se poderá enunciar, tal como podemos ver na natureza do círculo todas as propriedades que dele se podem deduzir. Mas, parece que com isso se destruirá a diferença entre verdades contingentes e necessárias, que não haverá mais lugar para a liberdade humana, e que uma fatalidade absoluta reinará em todas as nossas ações bem como em todo o resto dos acontecimentos do mundo. ${ }^{11}$
\end{abstract}

Em primeiro lugar, deve-se considerar que Leibniz era um matemático, desse modo, analisava o mundo com um olhar estatístico, ou seja, entendia que, de acordo com a natureza de cada substância, a probabilidade de que certos acontecimentos lhe ocorram é superior do que outros. No entanto, esse raciocínio é muito mais complexo do que parece, afinal, envolve questões relacionadas à necessidade e à contingência, causas eficientes e finais, conforme visto no início do artigo.

Entende-se por contingência “(...) aquela indiferença do ser aí existente, que, mesmo existente, pode sempre não existir”. (Cirne-Lima, 1996, p. 24). Ou seja, quando Leibniz afirma que cada substância carrega consigo a contingência, ele está assumindo este princípio para a sua teoria. O que Leibniz não assume é o acaso, pois em sua filosofia nada acontece por acaso, desenvolvendo, desse modo, o princípio da razão suficiente:

Este princípio exige que tudo o que existe ou acontece tenha uma razão para isso mesmo. Pode acontecer que não a descortinemos porque não se deduz necessariamente e porque exigiria uma análise integral do mundo real que o homem é incapaz de fazer. Mas a razão suficiente existe na noção de cada substância e só Deus a entende de forma absoluta. ${ }^{12}$

\footnotetext{
${ }^{10}$ LEIBNIZ, 1985, p. 27 e 39.

${ }^{11}$ LEIBNIZ, 1985, p. 33.

${ }^{12}$ LEIBNIZ, 1985, p. 34.
}

\begin{tabular}{|c|c|c|c|c|c|}
\hline intuitio & $\begin{array}{c}\text { ISSN } \\
1983-4012\end{array}$ & Porto Alegre & Vol.9- $\mathrm{N}^{\circ} .1$ & $\begin{array}{l}\text { Julho } \\
2016\end{array}$ & p.53-67 \\
\hline
\end{tabular}


Assim, levando em consideração os desígnios divinos, Leibniz não tenta, com sua teoria, determinar porque certas coisas acontecem ao invés de outras, contudo, prevalece com o seu raciocínio matemático quando afirma que os indivíduos não são capazes de fazer uma análise completa do mundo real, isto é, de todas as possibilidades possíveis de ocorrer à uma determinada mônada, de acordo com o seu mundo e a sua natureza. O que não significa, por outro lado, que a razão para que determinado acontecimento tenha ocorrido não esteja previamente contida dentro deste leque de possibilidades.

Já sobre a necessidade desta ocorrência, Leibniz (1985, p. 36) é enfático ao dizer que “(...) nada é necessário, se o seu oposto for possível. Ou, em outras palavras, o necessário é somente aquilo que, apesar de todas as contingências, prevalece simplesmente porque não existe possibilidade de acontecer de outro modo. E é justamente nesse ponto que a consciência e seu caráter reflexivo constituem uma parte importante de sua filosofia:

A isto respondo que importa fazer distinção entre o que é certo e o que é necessário: todos estão de acordo que os futuros contingentes são seguros, já que Deus os prevê, mas nem por isso se reconhece que sejam necessários. Mas (dirse-á), se alguma conclusão se pode deduzir infalivelmente de uma definição ou noção, será necessária. E nós sustentamos que tudo o que tem de acontecer a alguém está já compreendido virtualmente na sua natureza ou noção, como as propriedades o estão na definição do círculo; assim, a dificuldade subsiste ainda. Para resolver solidamente, digo que a conexão ou consecução é de duas espécies: uma é absolutamente necessária, pelo que seu contrário implica contradição, e esta dedução faz-se nas verdades eternas como as da geometria; a outra é apenas necessária ex hypothesi; e, por assim dizer, acidentalmente, e é contingente em si mesma quando o contrário nada implica. ${ }^{13}$

Segundo a teoria de Leibniz, algo somente pode ser considerado necessário de fato se o seu oposto implicar em contradição, e como o Princípio de Não-Contradição afirma que “(...) duas proposições contraditoriamente opostas não podem ser simultaneamente verdadeiras, nem simultaneamente falsas. Se uma delas é verdadeira, a outra tem que ser falsa. (Cirne-Lima, 1996, p.13), isso significa que algo somente pode ser considerado de fato necessário se o seu oposto for impossível de ocorrer. Caso contrário, isto é, se existirem outras possibilidades possíveis de efetivação, este algo deve ser entendido como contingente. "Há uma conexão necessária nas verdades de razão (como as da geometria); e uma conexão contingente no encadeamento das verdades de fato que podiam não ter acontecido, porque o seu contrário não implica contradição”. (Leibniz, 1985, p. 34).

Entrementes, de acordo com o princípio da razão suficiente de Leibniz, tanto os acontecimentos necessários quanto os contingentes possuem uma razão de ser, sendo que os acontecimentos necessários (aqueles que não podem ser de outra forma) são de ordem estritamente divina, onde Deus, podendo optar entre diversos mundos possíveis, ordenou as coisas de modo que constituíssem o melhor mundo possível,

\footnotetext{
${ }^{13}$ LEIBNIZ, 1985, p. 34.
}

\begin{tabular}{|c|c|c|c|c|c|}
\hline intuitio & $\begin{array}{c}\text { ISSN } \\
1983-4012\end{array}$ & Porto Alegre & Vol.9- No .1 & $\begin{array}{c}\text { Julho } \\
2016\end{array}$ & p.53-67 \\
\hline
\end{tabular}


e neste, também a natureza de todas as coisas é ordenada de modo que ocorra o melhor acontecimento possível dentre as possibilidades pré-existent:

(...) supõe a sequência das coisas que Deus livremente escolheu e que está baseada no primeiro decreto livre de Deus, o qual estabelece fazer sempre o mais perfeito, e no decreto que Deus fez (a seguir ao primeiro) a propósito da natureza humana, a saber, que o homem fará sempre (embora livremente) o que lhe parecer melhor. Ora, toda a verdade baseada nestas espécies de decretos é contingente, ainda que seja certa; pois, estes decretos não mudam a possibilidade das coisas e, como já disse, embora Deus escolha seguramente sempre o melhor, isso não impede que o menos perfeito exista e continue a ser possível em si mesmo ${ }^{14}$

Dessa forma, Leibniz acreditava que existe uma ordem, uma "harmonia preestabelecida" oculta na natureza, que faz com que dentro da cadeia de possibilidades pré-existentes se efetive sempre o que há de melhor. E Leibniz não aplica essa teoria apenas àquilo que é macro como o universo e a natureza, mas também a todas as substâncias existentes, uma vez que elas mesmas somente vieram a existir por conta dessa ordem, desse grau mínimo de coerência necessário para que as coisas venham a ser.

Nesse sentido, Leibniz entende que cada mônada contém esse código intrínseco, o que explica a sua teoria sobre o uno, pois a harmonia que faz com que as coisas mantenham uma certa coerência, para Leibniz, não vem de fora, mas já está presente na natureza de cada substância que, ao refleti-la no exterior, se assemelha às demais, criando uma espécie de sincronia, que ele chamou de harmonia preestabelecida. "Embora todos exprimam os mesmos fenômenos, não é por isso que as suas expressões são perfeitamente semelhantes, basta que sejam proporcionais (...)”. (Leibniz, 1985, p. 38)

Cada substância é como um mundo à parte, independente de toda outra coisa, fora de Deus; assim, todos os nossos fenômenos, isto é, tudo o que nos possa alguma vez acontecer, são apenas consequências do nosso ser; e como estes fenômenos guardam uma certa ordem conforme à nossa natureza ou, por assim dizer, ao mundo que está em nós e que faz que possamos fazer observações úteis para regular a nossa conduta, justificadas pelo resultado dos fenômenos futuros, e que assim possamos frequentemente julgar o futuro pelo passado sem nos enganarmos, isso bastaria para dizer que tais fenômenos são verdadeiros sem nos preocuparmos se estão fora de nós e se os outros deles se apercebem também; contudo, é muito certo que as percepções ou expressões de todas as substâncias se correspondem entre si de tal forma que, ao seguir cada um com cuidado certas razões ou leis que observou, coincide com outro que faz o mesmo ${ }^{15}$

Leibniz foi, seguramente, o maior matemático de seu tempo, criando conceitos como o da energia cinética, das proposições sintéticas e analíticas e do cálculo infinitesimal. Além destes, Leibniz acreditava que a constituição última da matéria não era material em si mesma, mas sim centros imateriais de atividade, aos quais chamou de mônadas. Hoje se sabe que toda a matéria é redutível à energia, porém em

\footnotetext{
${ }^{14}$ LEIBNIZ, 1985, p. 36.

${ }^{15}$ LEIBNIZ, 1985, p. 38.
}

\begin{tabular}{|c|c|l|l|l|l|}
\hline intuitio & $\begin{array}{c}\text { ISSN } \\
1983-4012\end{array}$ & Porto Alegre & Vol.9- $\mathrm{N}^{\circ} .1$ & $\begin{array}{l}\text { Julho } \\
2016\end{array}$ & p.53-67 \\
\hline
\end{tabular}


sua época tudo o que se podia imaginar a esse respeito estava ligado à mente, à alma, ao espírito. E foi justamente por essa via que Leibniz tentou se expressar.

Ele viu os pontos de propensão à atividade que constituem a matéria como se fossem manchas de consciência ocupando pontos no espaço. Chamou-as de "mônadas", e acreditava que tudo era composto por elas. Embora visse todas as mônadas como sem espaço dentro de si mesmas, também as via como diferindo amplamente em intensidade, desde as que compõem a matéria inorgânica, no nível mais baixo da escala, até as mentes humanas, cada uma das quais é uma mônada, e depois até Deus, que também é uma mônada. Cada mônada é um ponto de vista em relação ao resto da realidade - seu próprio mundo. Desse modo, as mônadas não interagem - por exemplo, nós, humanos, não compartilhamos a consciência uns dos outros: somos o que Leibniz chamou "sem janelas". Mas todos nós, mônadas, fomos criados por Deus para existir juntos no mesmo mundo, por isso ele ordenou uma harmonia de função para nós, de modo que as atividades de todos e de tudo possam coexistir ${ }^{16}$

Enquanto matemático e filósofo racionalista, Leibniz não podia conceber que esses centros imateriais de atividade, bem como a harmonia preestabelecida intrínseca a cada um deles, pudessem simplesmente surgir do nada. Achava mais plausível a ideia de que essas coisas surgissem a partir de um Ser necessário, que para ele era Deus. "Só Deus (...) é causa dessa correspondência dos seus fenômenos e faz que o que é particular para um seja público para todos; de outro modo, não haveria conexão alguma. (Leibniz, 1985, p. 39).

Para fundamentar essa teoria, Leibniz utilizou mais uma vez a lógica, formulando cinco premissas fundamentais, conforme segue:

Premissa 1: Tudo o que existe possui uma explicação para sua existência, seja na necessidade de sua própria natureza (para Leibniz, qualquer ente necessário deve ser capaz de se configurar como causa primeira), seja por meio de uma explicação externa (a razão suficiente), onde todas as coisas são vistas como produtos tanto da causalidade eficiente como da final (conforme exposto na primeira parte do presente artigo).

Ora, se essa primeira premissa de que tudo o que existe possui uma explicação for negada, então nega-se também os pilares fundamentadores da própria Ciência, uma vez que, nesse caso, as coisas poderiam simplesmente surgir no mundo, sem motivo algum.

Premissa 2: $O$ universo possui uma explicação para sua existência e tal explicação está fundamentada em um Ser necessário. Sobre essa premissa, a primeira pergunta a se fazer é: porque o universo não poderia ser necessário em si mesmo, sendo a sua própria explicação, ao invés de exigir a existência de um Ser necessário que lhe antecede?

Para responder essa pergunta é preciso fazer a seguinte análise: de acordo com o argumento cosmológico de Leibniz, para que o universo seja necessário em si, ele deve ser eterno e imutável. Apesar

${ }^{16}$ MAGEE, 2011, p. 99.

\begin{tabular}{|c|c|c|c|c|c|}
\hline intuitio & $\begin{array}{c}\text { ISSN } \\
1983-4012\end{array}$ & Porto Alegre & Vol.9- No .1 & $\begin{array}{c}\text { Julho } \\
2016\end{array}$ & p.53-67 \\
\hline
\end{tabular}


de Leibniz, à sua época, não ter a favor de sua teoria as evidências científicas possuídas hoje, ele considerava que o universo não fosse estanque, e por isso mesmo, não poderia ser a causa primeira de todas as coisas.

Enquanto pensadores anteriores consideraram a matéria inerte, e o movimento como causado por essa matéria inerte recebendo algum tipo de impulso, Leibniz via o movimento - ou, de todo modo, a atividade, ou a propensão à atividade como inerente à natureza da matéria ${ }^{17}$

Assim sendo, considerando que o universo não seja eterno e tão pouco imutável, não é possível que ele seja a causa última de si mesmo, o que, de acordo com a teoria de Leibniz, implica na existência de um Ser necessário anterior ao próprio universo, pois pela lógica leibniziana, tão pouco é possível que o universo tenha surgido do nada. Em outras palavras, a questão posta aqui de forma atualizada é: como o nada colidiria com o nada para formar tudo o que existe se nem mesmo as partículas subatômicas vêm à tona a partir do nada, mas sim de uma flutuação de energia contida no próprio vácuo?

Nesse ponto, a fim de evitar o problema do eterno retorno ao infinito, só resta encarar de frente o problema de um começo cósmico, que Leibniz resolve com as próximas três premissas, finalizando assim, a cadeia de explicações por meio da existência de um Ser necessário criador de tudo o que existe.

Premissa 3: $O$ universo existe.

Premissa 4: Portanto, a partir das premissas 1 e 3, o universo possui uma explicação para a sua própria existência.

Premissa 5: Assim sendo, a partir das premissas 2 e 4, a explicação sobre a existência do universo está fundamentada em um Ser necessário (Deus, para Leibniz).

Deveras, Leibniz acreditava que o universo foi concebido por um Ser que logicamente só poderia ser necessário, uma vez que seria Ele a causa de todas as outras coisas. Ou seja, um ser eterno, imutável e também consciente, uma vez que o mesmo deve ser capaz de fazer algo por si mesmo enquanto causa primeira, o que exclui a possibilidade do universo ter se constituído a partir de uma substância inconsciente, e, portanto, ao acaso.

\section{Considerações finais}

Enquanto Leibniz entende a alma humana como uma mônada, constituída em última instância por uma substância simples e única, Hegel, ao contrário, entende que a consciência somente se desenvolve em constante relação com o todo; sozinha, porém, nada mais é do que o nada absoluto. No entanto, as duas teorias possuem um ponto em comum: a existência de uma tendência ao equilíbrio que Leibniz chamou de

\footnotetext{
${ }^{17}$ MAGEE, 2011, p. 99.
}

\begin{tabular}{|c|c|c|c|c|c|}
\hline intuitio & $\begin{array}{c}\text { ISSN } \\
1983-4012\end{array}$ & Porto Alegre & Vol.9- $\mathrm{N}^{\circ} .1$ & $\begin{array}{l}\text { Julho } \\
2016\end{array}$ & p.53-67 \\
\hline
\end{tabular}


harmonia preestabelecida, a qual ele acreditava que fizesse com que, dentro da cadeia de possibilidades pré-existentes, se efetive sempre o que há de melhor. Já em Hegel, a coerência é tida como necessidade absoluta para a consciência, e provém a partir do constante jogo de forças entre o singular e o universal, imposto pela própria consciência em sua busca por conhecimento. Em suma, mesmo tratando-se de teorias opostas, ambos entendem a coerência como requisito fundamental ao desenvolvimento e à evolução do pensamento humano.

\section{Referências}

CIRNE-LIMA, Carlos. Sobre a Contradição. Porto Alegre: EDIPUCRS, 2 a edição, 1996.

HEGEL, G.W.F. Enciclopédia das Ciências Filosóficas em Compêndio. I A Ciência da Lógica. São Paulo: Edições Loyola, 2012, $3^{\text {a }}$ edição.

. Fenomenologia do Espírito. Rio de Janeiro: Editora Zahar, 2007, $4^{\mathrm{a}}$ ed.

LEIBNIZ, G.W. Discurso da Metafísica. São Paulo: Editora Martins Fontes, 1985.

LUFT, Eduardo. Para uma crítica interna ao sistema de Hegel. Porto Alegre: EDIPUCRS, 1995.

MAGEE, Bryan. História da Filosofia. São Paulo: Edições Loyola, 2011, $5^{\text {a }}$ edição.

Recebido em: 22/02/2016

Aprovado para a publicação em: 06/05/2016

\begin{tabular}{|l|c|c|c|c|c|}
\hline intuitio & $\begin{array}{c}\text { ISSN } \\
1983-4012\end{array}$ & Porto Alegre & Vol.9- No.1 & $\begin{array}{c}\text { Julho } \\
2016\end{array}$ & p.53-67 \\
\hline
\end{tabular}

